East African Medical Journal Vol. 77 No 7 July 2000

ANTHROPOMETRIC PROFILE OF URBAN ADULT BLACK MALAWIANS

B.C. Msamati, MD, PhD and P.S. Igbigbi, MBBS, MSc, Department of Anatomy, College of Medicine, University of Malawi, Private Bag 360, Chichiri, Blantyre 3, Malawi

Request for reprints to: Professor B.C. Msamati, Department of Anatomy, College of Medicine, University of Malawi, Private Bag 360, Blantyre 3, Malawi

\title{
ANTHROPOMETRIC PROFILE OF URBAN ADULT BLACK MALAWIANS
}

\author{
B.C. MSAMATI and P.S. IGBIGBI
}

\begin{abstract}
Objective: To determine the anthropometric profile of urban adult black Malawians. Design: A cross sectional study of adult subjects. Setting: The subjects were recruited from two townships of Kachere and Bangwe, Blantyre. Subjects: Eight hundred and ninety eight urban adults, 583 males and 315 females aged sixteen to sixty years. were randomly selected. Only those who could identify both parents and grandparents as Malawians were included. Pregnant women and physically disabled persons were excluded from the study.

Main outcome measures: Height, weight, body mass index (BMI), hip and waist circumferences and waist: hip ratio $(\mathrm{W}: \mathrm{H})$ were determined.

Results: The mean height of men was $166( \pm 6 \mathrm{SD}) \mathrm{cm}$ and that of women $155( \pm 9.4 \mathrm{SD}) \mathrm{cm}$. The mean weight, BMI, hip and waist circumferences for men were $60( \pm 6 \mathrm{SD}) \mathrm{kg}, 21.56 \pm 1.71$ $\mathrm{SD}, 92 \pm 4.4 \mathrm{SD} \mathrm{cm}$ and $75 \pm 6.3 \mathrm{SD} \mathrm{cm}$ and for women $62( \pm 14 \mathrm{SD}) \mathrm{kg}, 25.54( \pm 5.59 \mathrm{SD}), 99$ $( \pm 12 S D) \mathrm{cm}$ and $79( \pm 10 S D) \mathrm{cm}$, respectively. Only women were found to be obese $(11.43 \%$, BMI $\geq 30)$. The prevalence of underweight in men (BMI $<20)$ was $20 \%$ and $9.21 \%$, in women (BMI < 19). More than three per cent of the men were overweight $(B M I \geq 25)$ but none was obese (BMI $\geq 30$ ) while $37.14 \%$ of the women were overweight (BMI $\geq 24)$.

Conclusion: These findings suggest that obesity is a potential problem among urban females, and the roles of nutritional, metabolic and genetic factors are discussed.
\end{abstract}

\section{INTRODUCTION}

Anthropometry is a vital tool in epidemiological studies, especially with regard to conditions like coronary heart disease (1-2), respiratory disease(3), hypertension(4) and diabetes(5). In spite of this, only very few anthropometric studies have been reported in Africans. One reason for this view may be the traditionally held notion that anthropometric study of the Black Africans tends to focus on under-nourishment rather than overweight. In sub-Saharan Africa most anthropometric studies have been restricted to children, especially in South Africa (6,7), Zimbabwe(8), and fewer studies have been reported in adults in Nigeria (9), Zimbabwe (10) and South Africans (11).

The most commonly used anthropometric variable in epidemiological studies is the body mass index (BMI). This index closely correlates with adiposity (12) and has been used to assess body fat or obesity $(13,14)$. Nevertheless, there appear to be no published reports on anthropometric profiles of adult blacks in Malawi, a country where more than $50 \%$ of children are stunted and generally adults appear short in stature. This is generally attributed to deficiencies in iodine and other micro nutrients, especially zinc (15). It is hoped, therefore, that this study would provide useful baseline data when assessing the nutritional status of the adult black subjects and when planning strategies to combat adult malnutrition and diseases associated with obesity at either end of the weight spectrum.

\section{MATERIALS AND METHODS}

A cross sectional sample of 898 adult subjects, selected randomly (every third person) from among healthy subjects, were recruited from Kachere and Bangwe areas of Blantyre City. These are townships where the majority of people earn low incomes. Only those who could identify both parents and grandparents as Malawians were included. Pregnant women and physically disabled persons were excluded from the study.

Body weight: Weight was recorded to the nearest $0.5 \mathrm{~kg}$ using a professional health-o-meter scale (supplied by Health o meter Inc, Illinois, USA) calibrated in $\mathrm{kg}$. All subjects wore light clothing and removed their shoes before weight measurements were taken. 
Height, hip and waist circumferences: The Harpenden anthropometer was used to measure heights to the nearest $0.1 \mathrm{~cm}$. For each height reading, the heel, buttocks and shoulder blades were in contact with the vertical surface of the anthropometer. The measurement of waist circumference (in $\mathrm{cm}$ ) was taken midway between the subcostal margin and iliac crest while the hip circumference (in $\mathrm{cm}$ ) was taken at the point of maximum circumference over the buttock. To minimise intra- and interobserver errors, two people had been trained to take all measurements. A male took the circumferences for male subjects and a female for female recruits in keeping with local tradition. Technical errors of measurements and reliability were computed(16) and reliabilities for all measurements were higher than 0.85 , hence the technical errors were acceptable.

The mean BMI and waist: hip (W: H) ratio were calculated for each subject and Bray's classification (17) of underweight, normal weight, overweight and obesity using the BMI was used in this study (Table 2). The results were analysed using the SAS statistical package for Windows version 6.08.

\section{RESULTS}

There were 583 males and 315 females, aged 16 - 59 years in the sample. Table 1 shows the anthropometric data and means of the subjects studied. Females were generally heavier than males in all age groups. The overall mean height of females was at least $10 \mathrm{~cm}$ shorter than males in all age groups (166 cm male and $155 \mathrm{~cm}$ female) but their hips were larger than those of males. This was also true of the waist circumferences except for those in the younger (16 - 24 years) age group (Table 1).

The male/female differences in height, weight, BMI, hip and waist circumferences as well as $\mathrm{W}$ : $\mathrm{H}$ ratios were highly statistically significant $(\mathrm{p}<0.001)$ with respect to height, BMI, and the hip circumference, significant ( $p<0.05$ ) with regard to waist circumference and statistically not significant with weight and $\mathrm{W}$ : $\mathrm{H}$ ratios.

Comparisons of the mean BMIs showed that those of females were generally higher than those of males, but males showed larger mean $\mathrm{W}$ : $\mathrm{H}$ ratios. The BMI in females increased to a maximum (28.57) in the 34 - 42 year age group and decreased (24.73) as the females approached the 43 - 51 year age group (Table 1).

Table 2 shows the prevalence of underweight, normal weight, overweight and obesity using BMI. Overall, twenty per cent of the men $(n=117)$ were underweight and these

Table 1

Anthropometric characteristics of urban adults subjects in Blantyre City-Malawi

\begin{tabular}{|c|c|c|c|c|c|c|c|c|c|c|c|}
\hline \multirow[b]{2}{*}{ Variable } & \multicolumn{5}{|c|}{ Males by age groups } & \multicolumn{5}{|c|}{ Females by age groups } & \multirow[b]{2}{*}{$\begin{array}{r}16-51 \\
\mathrm{n}=315\end{array}$} \\
\hline & $\begin{array}{l}16-24 \\
n=252\end{array}$ & $\begin{array}{l}25-33 \\
n=189\end{array}$ & $\begin{array}{c}34-42 \\
n=54\end{array}$ & $\begin{array}{r}43-51 \\
n=63\end{array}$ & $\begin{array}{c}52-60 \\
n=18\end{array}$ & $\begin{array}{l}16-60 \\
n=585\end{array}$ & $\begin{array}{l}16-24 \\
n=108\end{array}$ & $\begin{array}{r}25-33 \\
\mathrm{n}=36\end{array}$ & $\begin{array}{l}34-42 \\
n=72\end{array}$ & $\begin{array}{l}43-51 \\
n=99\end{array}$ & \\
\hline Height $(\mathrm{cm})$ & $165.73(5.24$ & $168.25(598)$ & $165.40(10.37)$ & $165.71(5.62)$ & $165.00(283)$ & $166.02(1.28)$ & $155.46(5.40)$ & $154.78(3.40)$ & $157.39(360)$ & $154.38(5.25)$ & $155.50(1.30)$ \\
\hline Weight (kg) & $58.41(506)$ & $60.17(5.87)$ & 63.25 (7 23) & $58.13(4.66)$ & $68.50(9.19)$ & $61.69(4.32)$ & $59.86(9.34)$ & $59.38(6.95)$ & $70.48(15.78)$ & $59.20[20.26)$ & $62.23(5.51)$ \\
\hline BMI $\left(\mathrm{kg} / \mathrm{m}^{2}\right)$ & $21.25(1.34)$ & $21.24(1.55)$ & $22.72(2.70)$ & $21.16(1.15)$ & $25.12(2.51)$ & $22.30(1.71)$ & $24.68(3.01)$ & $24.72(1.86)$ & $28.57(6.94)$ & $24.73(7.87)$ & $25.68(1.93)$ \\
\hline Hip circumference & $91.02(3.25)$ & $91.64(4.77)$ & $93.75(6.65)$ & $92.27(4.96)$ & $96.50(4.95)$ & ) $93.04(2.19)$ & $97.42(7.56)$ & $97.63(2.93)$ & $105.38(12.46)$ & $98.10[17.02)$ & $99.63(3.84)$ \\
\hline Waist circumference & e $74.09(3.56)$ & $74.42(4.08)$ & $75.55(15.83)$ & $79.29(7.08)$ & $85.00(1.41)$ & $77.67(4.59)$ & $75.87[6.39]$ & $76.25(4.57)$ & $85.56(12.09)$ & $79.80(12.93)$ & $79.37(4.49)$ \\
\hline \multicolumn{12}{|l|}{ Waist: hip (W:H) } \\
\hline ratio & $0.82(0.03)$ & $0.81(0.03)$ & $0.81(0.16)$ & $0.83[0.08]$ & $0.88(0.03)$ & $0.83(0.03)$ & $0.77(0.04)$ & $0.78(0.02)$ & $0.81(0.04)$ & $0.82(0.04)$ & $0.80(0.02)$ \\
\hline
\end{tabular}

()$=$ Standard deviation

Table 2

Anthropometric categories of black adult Malawian subjects expressed as percentages

\begin{tabular}{|c|c|c|c|c|c|c|c|c|c|c|c|}
\hline \multirow{2}{*}{$\begin{array}{l}\text { Classification of adult profiles } \\
\text { by Bray, } 1978\end{array}$} & \multicolumn{5}{|c|}{ Males by age groups } & \multicolumn{6}{|c|}{ Females by age groups } \\
\hline & $16-24$ & $25-33$ & $34-42$ & $43-51$ & $52-60$ & $16-60$ & $16-24$ & $25-33$ & $34-42$ & $43-51$ & $16-51$ \\
\hline \multicolumn{12}{|l|}{ Under weight } \\
\hline Male BMI $<20$, female $<19$ & 21.43 & 10.05 & 16.67 & 14.29 & 0 & 20 & 0 & 0 & 12.5 & 18.18 & 9.21 \\
\hline \multicolumn{12}{|l|}{ Normal weight } \\
\hline Male BMI $20<25$, female $19<25$ & 78.57 & 80.95 & 66.66 & 85.71 & 50 & 76.92 & 58.33 & 50 & 0 & 45.46 & 42.22 \\
\hline \multicolumn{12}{|l|}{ Overweight } \\
\hline Male BMI $25<30$, female $24<30$ & 0 & 0 & 16.67 & 0 & 50 & 3.08 & 41.67 & 50 & 62.5 & 18.18 & 37.14 \\
\hline Obese: $\mathrm{BMI}>30$ & 0 & 0 & 0 & 0 & 0 & 0 & 0 & 0 & 25 & 18.18 & 11.43 \\
\hline
\end{tabular}


were in the younger (16 - 24 year) age group (9.23\%). Most men, however, were of normal weight, with only 18 (3.08\%) of them being overweight. No man was obese but overweight men were in the $34-42$ year and 55 - 60 year age groups.

Only $29(9.21 \%)$ of the women were underweight, $117(37.14 \%)$ being overweight and $36(11.43 \%)$ were obese (Table 3 ). Obesity was the most striking feature of the women's anthropometry. Most of the women with normal weight were in the $16-24$ year age group. All obese women and most of the overweight women were in the age range of 34 years and above. Only $14.29 \%(n=$ $54)$ of the younger women (16 - 24 years) were overweight but none of them obese. Women therefore showed far greater age-related increase in overweight and obesity than men did.

Table 3

Comparison of prevalence of obesity (BMI $\geq 30)$ in African and Caucasian subjects

\begin{tabular}{|c|c|c|c|c|c|}
\hline Author(s) & Area & Race & $\begin{array}{l}\text { Age } \\
\text { range }\end{array}$ & $\begin{array}{l}\text { Obesity in } \\
\text { males }(\%)\end{array}$ & $\begin{array}{l}\text { Obesity in } \\
\text { females (\%) }\end{array}$ \\
\hline Present study, 1999 & Blantyre City & African & $16-59$ & 0 & 11.43 \\
\hline Zinyowera et al., 1992 & Harare - urban \& rural & African & $18-51^{*}$ & 0 & 0 \\
\hline Seedat et al., 1990 & Urban Durban & Indian* & $25-69$ & 3.5 & 17.6 \\
\hline Steyn et al., 1990 & Urban Cape Town & African & $15-64$ & 7.9 & 34.4 \\
\hline Mollentze et al., 1990 & Rural Qwaqwa & African* & $25-64$ & 12.7 & 40.2 \\
\hline Mollentze et al., 1990 & Urban Manguag & African* & $25-69$ & 12.9 & 43.9 \\
\hline Jooste et al., 1988 & Rural Western Cape & White * & $25-64$ & 17.6 & 20.4 \\
\hline Garrow, 1983 & U.S.A & Black* & Adults & 16.0 & 40.50 \\
\hline Steyn et al., 1982 & Urban Cape Town & Mixed* & $25-64$ & 7.2 & 31.4 \\
\hline
\end{tabular}

* Cited from 11 (Steyn et al., 1998)

Table 4

Comparison of the mean height (in cm) in African and Caucasian subjects

\begin{tabular}{|c|c|c|c|c|c|c|}
\hline \multirow[t]{2}{*}{ Author(s) } & \multirow[t]{2}{*}{ Area } & \multirow[t]{2}{*}{ Age } & \multicolumn{2}{|c|}{ Males } & \multicolumn{2}{|c|}{ Females } \\
\hline & & & Height & SD & Height & SD \\
\hline Present study, 1999 & Blantyre-urban & $16-59$ & 166.0 & 6.0 & 155.0 & 9.4 \\
\hline Zinyowera et al., 1992 & Harare-urban \& rural & $18-51^{*}$ & 170.0 & 0.8 & 160.0 & 1.0 \\
\hline Steyn et al., 1990 & Urban Cape Town & $15-64$ & 168.3 & 6.8 & 158.3 & 6.9 \\
\hline Wing et al., 1989 & USA urban blacks & $42-50$ & - & - & 162.4 & 6.3 \\
\hline DeVilliers, 1987 & Rural Kwazulu & $24-46$ & - & - & 158.0 & 6.0 \\
\hline O’Keefe et al., 1985 & Urban Durban & $42(16) *$ & 171.0 & 8.0 & 161.0 & 7.0 \\
\hline O’Keefe et al., 1985 & Rural Kwazulu & $37(17) *$ & 165.0 & 7.0 & 156.0 & 6.0 \\
\hline Ndaba \& O’Keefe, 1985 & Rural Kwazulu & $41(19)^{*}$ & 166.0 & 7.0 & 158.0 & 1.2 \\
\hline Ostwald \& Gebre-Medhin, 1978 & Addis Ababa & $20-30$ & 168.0 & 6.3 & - & - \\
\hline Slome et al., 1960 & Urban Durban & $50-50 *$ & 165.5 & 6.1 & 155.3 & 5.8 \\
\hline Jellife et al., & USA Caucasian & - & 176.8 & 6.1 & 163.7 & 6.3 \\
\hline
\end{tabular}

*Cited from 11 (Steyn et al., 1998) 
Tables 3 and 4 compare obesity (BMI $\geq 30)$ and mean heights of adult Africans and Caucasians in various studies. The mean height of male and female subjects in the present study compared well with previous studies in Africans.

\section{DISCUSSION}

About one fifth of the young male Malawians sampled were underweight compared to one tenth of the females studied. Approximately half of the female subjects were either overweight or obese; in contrast only $3.08 \%$ of the men were overweight and none was obese. In a similar study carried out among black subjects in Zimbabwe, Zinyowera et al (10) demonstrated that obesity was not a problem in a countrywide sample of 775 males and 734 females. However, the prevalence of obesity of $11.43 \%$ found among women in the present study is much lower than that seen in South African blacks where $34.4 \%$ of the women and $7.9 \%$ of men were reported obese(11). Although our findings showed the lowest prevalence of obesity when compared to the other studies (Table 3), the results demonstrate the existence of obesity amongst females in Malawi. The present study, however, accords with black American studies where females are reported to be more obese than their male counterpart (18).

The statistically significant differences exhibited by height and BMI confirm the results reported by other studies. In a recent study Michels, Greenland and Rosner(12), have revealed that although BMI may show some aspects of body composition, it does not give all information on body size. They argued that BMI alone is often an inadequate anthropometric variable, and waist and hip circumferences were often needed in addition to BMI(12). Both indices have been utilised in this study. The mean BMI in females was found to increase to a maximum of 28.57 in the $34-42$ year age group and decreased to 24.73 as females approached 43 - 51 year age group. It has been suggested that females tend to store fat during the 34 - 42 year age group and lose some in the older age group $(10,12)$. Besides, it has been observed that childbearing must be considered as an important factor in any anthropometric assessments using BMI and $\mathrm{W}: \mathrm{H}$ ratios in females (10). In this case the contribution of high parity in Malawi cannot be excluded as a key factor in the present observations.

The mean W: $\mathrm{H}$ ratio was found to be higher in males than females, but the difference was not statistically significant (Table 1). Wider female pelves, necessary for childbearing, could be responsible for this finding. The $\mathrm{W}: \mathrm{H}$ ratio has been shown to be a good measure of adiposity particularly subcutaneous and intra-abdominal fat (17). Its usefulness lies more in the assessment of risk to health problems related to abdominal adiposity. Marwick(20) showed that when $\mathrm{W}$ : $\mathrm{H}$ ratio is below one, the individual is not at much risk to health problems associated with abdominal adiposity.
The BMIs and $\mathrm{W}: \mathrm{H}$ ratios have been found to have wide clinical and scientific applications $(8,17)$. Daly et al(8) suggested that the body weight and height might help to explain the lower incidence of a ischaemic heart diseases observed in African men to. On the other hand, Wells and Kopperschaar (21) observed that body weight and height are important for the assessment of the nutritional status of a subject. Since nutritional dwarfs have an appropriate weight for age and a low height for age, these authors recommend the use of local standards.

Several factors have been shown to influence obesity. In the adult subjects sampled in the present study, the prevalence of obesity is $11.43 \%$ among females and none was found in males. However, the prevalence of obesity among females appears to be lower than reported in South African women of other cultural groups (Table 3). On the other hand, the percentage of women classified as overweight in the present study $(37.14 \%)$ is similar to what was reported for South African women (36.4\%) (11). The studies from South Africa, Zimbabwe and currently Malawi suggest that metabolic and genetic factors could play a key role in explaining the sexual dimorphism exhibited here. In other studies Bray (17) and Thompson et al (19) have demonstrated that the risk of developing obesity-related conditions closely correlated with the distribution of body fat or fat patterning. Hence it is not a question of how much fat is in the body, but rather where the fat is located that determines the associated health risk(19).

Differences in diet, lifestyles and seasonal variations have been cited as possible reasons for the marked differences in obesity between the developed and developing countries $(13,14,17)$. In Africa, the nutrition studies in Ethiopia and Malawi suggest that there may be diet trends, which show that in rural areas less than ten per cent of dietary energy is derived from fat. In Mangochi district of Malawi, Huddle(22) and Ndekha et al(23), have reported seven and eight per cent respectively, of dietary energy as derived from fat. GebreMedhin and Gobezie(24) reported that ten per cent of the total daily energy intake was derived from fat among non-privileged primigravidae Ethiopian women in suburban areas of Addis Ababa. Tulle (25), on the other hand, reported more than $30 \%$ dietary energy from fat in urban subjects of Blantyre City in Malawi. These figures must be compared with WHO recommended lower and upper limits of $15 \%$ and $30 \%$, of dietary energy from fat (26). The studies in Malawi and Ethiopia, however, tend to suggest dietary transition from rural to urban settings and might explain the obesity in urban women observed in this study.

Further studies on occupations, lifestyles, diets and seasonal variations are called for in the African sub-region as these affect the nutritional status of adults (23). It is suggested that health-planning strategies must also address adult nutrition and obesity-related conditions in healthy adults as well as vulnerable groups of our populations as they migrate into towns and cities in search of better opportunities. 


\section{ACKNOWLEDGEMENTS}

To Ms Sarah Butao of the Department of Anatomy, College of Medicine, University of Malawi, for secretarial services.

\section{REFERENCES}

1. Rimm, E.B., Stampfer, M.J., Giovannucci, E., Ascherio, A., Spiegelmar, D., Colditz, G.A. and Willet, W.C. Body size and fat distribution as predictors of coronary heart disease among middleaged and older US men.Amer. J. Epidem. 1995; 141: 1117 - 1127.

2. Willet, W.C., Manson, J.E., Stampfer, M.J., Colditz, G.A., Rosner, B., Speizer, F.E. and Hennekens, C.H. Weight, weight change and coronary heart disease in women: risk within the "normal" range. J. Amer. Med. Ass. 1995; 273: 461 - 465.

3. Sanya, A.O. and Adesina, A.T. Relationship between estimated body fat and some respiratory function indices. Cent. Afr. J. Med. 1998; 44: 254 - 258.

4. Hovell, M.F. The experimental evidence for weight-loss treatment of essential hypertension: a critical review. Amer. Pub. Hlth. 1982; 72: 359 - 368.

5. World Health Organization Study Group. Diabetes mellitus. Technical Report Series No. 727. Geneva, Switzerland: WHO. 1985

6. Bourne, L.T., Langenhoven, M.L., Steyn, K., Jooste, P.L., Laubscher, J.A., and Bourne, D.E. Nutritional status of 3 - 6 yearold African children in the Cape Peninsula. East Afr. Med. J. 1994; 71: 695-702.

7. Steyn, K., Fourie, J.M., Rossouw, J.E., Langenhoven, M.L., Joubert, G. and Chalton, D.O. Anthropometric profile of the colored population of the Cape Peninsula. S.Afr. Med. J. 1990; 78: 68-72.

8. Daly, J., Tsomondo, E. and Jones, J. Height, weight and skin fold thickness of African school children. Cent. Afr. J. Med.1973; 19: 234- 236.

9. Adekolu, John, E.O. Some anthropometric attributes of a rural community in Nigeria. Afr. J. Med. Sci. 1 990; 19: 231- 235.

10. Zinyowera, T.S., Msamati, B.C. and Banadda, B.M. Obesity - Is it a problem in Black Zimbabweans? Cent. Afr. J. Med. 1994; 40: 33 - 38 .

11. Steyn, K., Bourne, L., Jooste, P., Fourie, J.M., Rossouw, K. and
Lombard, C. Anthropometric profile of a black population of the Cape Peninsula in South Africa. East Afr. Med. J. 1998; 75: 35 - 40.

12. Michels, K.B., Greenland, S., Rosner, B.A. Does Body Mass Index Adequately Capture the Relation of Body Composition and Body Size to Health Outcomes? Amer. J. Epidem. 1998; 147: 167-172.

13. Kholsa, T. and Lowe, C.R. Indices of obesity derived from body weight and height. Brit. J. Prevent. Soc. Med. 1967; 21: 122-128.

14. Waston, P.E., Waston, I.D. and Batt, R.D. Obesity indices. Amer. J. Clin. Nutr. 1979; 32: 736 - 737.

15. Ferguson, E.L., Gibson, R.S., Thompson, L.U. and Ounpuu, S. Dietary calcium, phytate and zinc intakes and the calcium phytate and zinc molar ratios of the diets of a selected group of East African children. Amer. J. Clin. Nutr. 1989; 50: $1450-1456$.

16. Ulijaszek, S.J. and Lourie, J.A. Errors of measurement. In: Anthropometry, the individual and the population, Eds Ulijaszek S.J. and Mascie-Taylor C. G. N. Cambridge University Press; 1994; 30- 35.

17. Bray, G.A. Definition, measurement and classification of the syndromes of obesity. Intern. J. Obesity. 1978; 2: 99-112.

18. Burke, G.L., Jacobs, D.R., Sprafa, J.M., Savage, P.J. and Sidney, S., Wagenknecht, L.E. Obesity and overweight in young adults: the Cardia study. Prevent. Med. 1990;19: 476 - 488.

19. Thompson, .C.J., Ryu J.E., Cravin, T.E., Kahl, F.R., Grouse, J.R. Central adipose distribution is related to coronary arteriosclerosis. Atherosclerosis and Thrombosis. 1991; 11: 327-333.

20. Marwick, C. "Desirable weight" goes up in New Guidelines. $J$. Amer. Med. Ass. 1991; 265: 17

21. Wells, T. and Kopperschaar H.P. Body composition measurements. J. Med. 1989; 35: 204 - 217.

22. Huddle, J.M. Energy intake, iron and zinc nutriture of pregnant women in rural Malawi. A. Ph.D. Thesis. University of Guelf, Canada, 1996.

23. Ndekha, M., Kulmala, T., Vaahtera, M., Cullinan, T., Salin M-L and Ashon P. Ecol. Food Nutr. 1999; 38: 1 -18.

24. Gebre-Medhin, M, Gubezie, A. Dietary intake in the third trimester of pregnancy and birth weight of offspring among non-privileged and privileged women. Amer. J. Clin. Nutr. 1975; 28: 1322 -1329.

25. Tulle, K. Personal communication. M. Med. Science Dissertation. University of Sheffield, 1998.

26. Garrow, J.S., James, W.P.T. Anthropometric characteristics of urban adult subjects in Blantyre City, Malawi.In: Human nutrition and dietetics. Churchill Livingston. 1993; Pp.782. 